\section{Nota}

Versión preliminar del capítulo publicado en Transformaciones de la Esfera Pública en Chile. Luchas Sociales, Espacio Público y Pluralismo Informativo, N. Del Valle, ed., RIL Editores, Santiago, 2018.

\section{INTRODUCCIÓN}

Antes del siglo XV, el conocimiento se difundía a través de libros manuscritos elaborados en monasterios por monjes y frailes copistas que se dedicaban casi exclusivamente a aquella ardua labor $^{1}$. Esta situación imponía barreras altísimas, tanto para la adquisición de capital cultural por parte de los individuos, como para la circulación de ideas e información. Si bien existían técnicas de impresión xilográficas, con base en planchas de madera, aquel método no resultaba adecuado ni conveniente dado su alto costo. Es por esto que los tipos móviles (tipografía) y la imprenta moderna de Gutenberg fueron aceptados y alcanzaron rápidamente un éxito tan grande.

${ }^{1}$ La popular novela histórica Il nome della rosa de Umberto Eco, publicada en 1980, ofrece una detallada descripción de la labor de los copistas al interior de una abadía.

\title{
Expansión de la esfera pública en Chile: Redes sociales, campañas electorales y participación digital
}

\author{
Bastián González-Bustamante ${ }^{1}$, Diego Barría ${ }^{2}$ \\ ${ }^{1}$ Profesor Instructor, Departamento de Gestión y Políticas Públicas, Facultad de Administración y \\ Economía, Universidad de Santiago de Chile, $₫$ bastian.gonzalez.b@usach.cl, ORCID iD \\ http://orcid.org/0000-0003-1510-6820 \\ ${ }^{2}$ Director y Profesor Asociado, Departamento de Gestión y Políticas Públicas, Facultad de \\ Administración y Economía, Universidad de Santiago de Chile, $\varangle$ diego.barria@usach.cl, ORCID \\ iD http://orcid.org/0000-0001-8906-9220
}


Este método aseguraba calidad y velocidad para la producción masiva de libros, lo que significó un avance que revolucionó la forma de transmitir el conocimiento y las ideas.

Desde entonces, y hasta la aparición de Internet, no habíamos vivido un cambio que tuviese un impacto tan importante en la forma que se crea y difunde el conocimiento y en la manera que las personas consumen información y adquieren capital cultural. Los primeros cambios comienzan a aparecer vertiginosamente a contar de fines de la década de 1950, con el surgimiento de los primeros servidores centrales. El proceso de evolución de la computación resulta totalmente sorprendente, ya que, en pocas décadas, nuestras sociedades han presenciado avances tecnológicos que la humanidad no había experimentado en toda su historia previa. Aquellos servidores centrales fueron reemplazados por los microprocesadores en la década de 1970, convirtiéndose estos en los primeros "computadores personales". A fines de la década de 1980 ya contábamos con computadores de escritorio y, a contar de 1990, se comenzó a popularizar el uso de la red. Por último, desde 2000 en adelante, hemos presenciado una masificación acelerada de Internet inalámbrica, telefonía móvil y un incremento sostenido de las tasas de penetración de banda ancha e Internet móvil en distintas partes del mundo. Todo esto no solo ha significado un cambio tecnológico acelerado que implicó un incremento sustancial en las capacidades productivas en distintas industrias, campos y disciplinas, sino que, además, ha alterado -y continúa haciéndolo- significativamente la forma en que las personas se comportan, interactúan y se informan a diario.

Estos cambios tecnológicos han generado un fuerte entusiasmo asociado a las potenciales bondades de estos avances para el mejoramiento de la democracia. Además, alteraron las prácticas en las campañas electorales. Durante el siglo XIX, por ejemplo, hubo quienes vieron en el telégrafo una posibilidad para aumentar la participación ciudadana. A esto se sumó el ferrocarril, que modificó, al menos en Chile, las prácticas políticas electorales² ${ }^{2}$ Más adelante, en el siglo XX, las campañas electorales en sistemas democráticos pasan a depender en gran medida de los medios de comunicación masivos, en particular de la televisión, fenómeno que se conoce como mediatización de la política (González-Bustamante y Henríquez 2013; Strömbäck 2008; Tironi y Cavallo 2007). Ya

\footnotetext{
${ }^{2}$ Esto implicó el surgimiento de las campañas electorales desplegadas territorialmente en la década de 1880. Para más detalles, véase Sagredo (2001).
} 
en las últimas décadas, el uso de nuevas tecnologías se ha intensificado en las campañas electorales, consolidándose el uso de redes sociales en línea como Twitter y Facebook (González-Bustamante 2014b; 2015b). Esto alteró la forma tradicional del trabajo político-electoral, emergiendo una dimensión vinculada a lo que la literatura especializada denomina "campaña digital", dentro de la cual, el uso de redes sociales, permite propagar $^{3}$ contenidos y posicionar a un candidato o tema específico (González-Bustamante y Sazo 2015b; Kaplan y Haenlein 2011). Un ejemplo de esto es lo que sucedió con los resultados de la encuesta del Centro de Estudios Públicos (CEP) de 2008 en Chile, donde el empresario Leonardo Farkas, ampliamente conocido en la prensa sensacionalista por sus excentricidades, obtuvo el $5 \%$ de las preferencias en miras de las elecciones presidenciales. Con ese resultado, Farkas superaba a figuras políticas consolidadas. Dos meses antes, existía una plataforma que promovía una eventual candidatura del empresario. Aunque finalmente Farkas no fue candidato, tanto la Web como su cuenta de Twitter permitieron que el empresario siga siendo reconocido por ciertos sectores como una potencial carta presidencial. En 2016, su cuenta de Twitter supera el millón de seguidores y sigue apareciendo en algunas encuestas de opinión pública en miras de las presidenciales de 2017.

Las instituciones, los partidos políticos y los movimientos sociales chilenos ya están en Internet desde la década pasada (Araya y Barría 2009; 2012; Araya et al. 2009). En consecuencia, la "política digital" se vincula, en gran medida, con las redes sociales (González-Bustamante 2014b; 2015b). En este contexto, resulta fundamental responder preguntas como, ¿de qué forma se han utilizado las redes sociales en las campañas electorales durante los últimos años?, ¿qué otros tipos de conversaciones o interacciones políticas se generan en la esfera digital desde estas plataformas? En este capítulo buscamos responder a estas interrogantes, explorando en el uso de redes sociales en campañas electorales y en conversaciones políticas en la esfera digital. Para esto, usamos como caso de estudio a Chile entre 2009 y 2015. Para facilitar la exposición del tema, dividimos el capítulo en tres apartados. En el primero, abordamos de forma resumida diversos asuntos teóricos relacionados con el avance de las tecnologías de información y su influencia en fenómenos democráticos y

\footnotetext{
${ }^{3}$ En este capítulo usamos el concepto propagar, sin embargo, la literatura académica utiliza con frecuencia el neologismo viralizar.
} 
electorales, con especial énfasis en la masificación del uso de redes sociales con fines electorales. En el segundo, abordaremos exploratoriamente el uso de redes sociales en las campañas electorales recientes, específicamente durante las últimas dos elecciones presidenciales (2009-2010 y 2013) y en otros hitos políticos como cuentas públicas o shocks sobre el sistema político, como escándalos de corrupción. El último corresponde a las conclusiones, donde retomamos las preguntas iniciales para responderlas a la luz del recorrido teórico-descriptivo realizado a lo largo del trabajo.

\section{LAS NUEVAS TECNOLOGÍAS Y SUS USOS ELECTORALES}

El vertiginoso avance tecnológico que el mundo ha experimentado desde mediados del siglo $\mathrm{XX}$, ha impulsado una serie de transformaciones sociales relevantes que, en diversos países, ha coincidido con un aumento sostenido de los niveles educacionales. Esto ha generado cambios en los flujos tradicionales de información, ocasionando que la relación entre instituciones/medios y ciudadanos/audiencias adquiera un carácter bidireccional y horizontal (Arriagada y Navia 2013; Del Valle 2016; González-Bustamante 2014a; 2015b; Hermida et al. 2012).

Estos cambios han implicado una reducción en los costos asociados al consumo de información y a la participación política (Rheingold 2000). Sobre este fenómeno, la literatura especializada tiende a distinguir dos posturas. La primera, el ciberoptimismo, se caracteriza por su entusiasmo sobre las potencialidades de las nuevas tecnologías asociadas a la reducción de costos en la participación y la posibilidad de disminuir la brecha entre gobernantes y gobernados. La segunda, el ciberpesimismo, es más bien escéptica, se centra en la idea de que puede existir un desplazamiento de procesos de socialización relevantes para generar un compromiso cívico real y tangible a través de una participación política (González-Bustamante y Henríquez 2013; Nie 2001). Por otra parte, otra idea recurrente asociada a esta desconfianza es que las desigualdades de la participación política convencional y contenciosa se replicarían en la esfera digital (Mossberger et al. 2008; Nam 2012).

Pese a la postura ciberpesimista, existe diversa literatura que señala que las nuevas tecnologías y, particularmente, las redes sociales online son potentes herramientas para la acción colectiva y la política contenciosa, ya que permiten movilizar apoyos y ampliar el alcance del conflicto (Castells 2012; Cammaerts 2012; Millaleo y Velasco 2013). En este contexto surge el concepto de 
activismo digital de Earl y Kimport (2011) para reinterpretar los marcos analíticos clásicos y el uso de repertorios de contención mediados por las nuevas tecnologías.

Las nuevas tecnologías y las redes sociales no solo son una potente herramienta para la acción colectiva, también han tenido influencia en otras dos dimensiones de la actividad política. Primero, en lo referente al gobierno electrónico, como herramienta para minimizar costos de información de la ciudadanía en los sistemas democráticos, permitiendo el surgimiento de nuevos mecanismos de responsabilidad vertical y horizontal (Altman y Luna 2009). En este contexto, las redes sociales posibilitan una colaboración donde los límites entre el gobierno y la ciudadanía se vuelven difusos (Linders 2012), además las instituciones están utilizando cada vez con mayor frecuencia nuevos canales de comunicación y plataformas como Twitter o Facebook (Sandoval-Almazán y Gil-García 2012a; 2012b; Rojas-Martín y Criado 2015). Por otra parte, en general, la evidencia sobre redes sociales tiende a demostrar que existe conversación política en Internet, sin embargo, aquel diálogo muchas veces no es "escuchado" por las autoridades e instituciones, lo que implica desaprovechar una oportunidad para potenciar una gobernanza en el marco de sistemas de big data, a través de la recolección de información dinámica sobre lo que opina la ciudadanía acerca de diversos asuntos (Couldry y Powell 2014).

La segunda dimensión tiene relación directamente con el uso de las nuevas tecnologías en el plano político-electoral. Al abordar los usos electorales de las nuevas tecnologías se vuelve central el concepto de imagen de marca o branding político. Este concepto está asociado a un proceso de construcción de una imagen, en el cual la gestión de recursos y activos es crucial para otorgar valor a la "marca", es decir, al candidato (González-Bustamante y Sazo 2015a). Ese valor agregado es lo que la literatura anglosajona describe como brand equity y permite que la marca sea percibida positivamente, en este caso, por los electores. En general, los procesos de branding permiten la creación de una identidad que el público reconoce y con la cual siente cercanía e incluso llega a identificarse (Marsh y Fawcett 2011). Evidentemente, todo candidato desea una imagen de marca positiva y debe ser cuidadoso con sus acciones en tiempos electorales, ya que todo lo que ocurre durante una campaña puede impactar de forma positiva o negativa en su imagen. 
La importancia del branding político depende del grado de visibilidad mediática de la campaña. Estas pueden ser de alta y baja visibilidad (Johnson-Cartee y Copeland 1991). En las campañas de baja visibilidad, son más relevantes las redes clientelares y el trabajo en terreno (despliegue territorial). Por otra parte, en aquellas de alta visibilidad resultan particularmente importantes los procesos de branding. Es aquí donde el uso de redes sociales, en el marco de una campaña digital, permite propagar contenidos y posicionar a un candidato y una imagen positiva (GonzálezBustamante y Sazo 2015b; Kaplan y Haenlein 2011).

Una campaña viral es un proceso de boca a boca electrónico en el cual los mensajes de propaganda se transmiten de forma exponencial por medio de dispositivos digitales (GonzálezBustamante y Sazo 2015b). Se llama viral por la modalidad en que se transmiten los mensajes, ya que se genera una replicación similar a la expansión de un virus, tanto por la velocidad como por la propagación. Estas campañas se generan, principalmente, a través de redes sociales online que permiten compartir información de todo tipo mediante Internet (Kaplan y Haenlein 2011). Estas redes son plataformas particularmente efectivas para las campañas virales, ya que los mensajes que allí se emiten se pueden propagar rápidamente, alcanzando altas tasas de replicación por otros usuarios de la Web.

La masificación de las redes sociales comienza a fines de la primera década de este siglo y se consolida durante los últimos cinco años, particularmente en países que tienen altas tasas de uso de banda ancha e Internet móvil. Entre las plataformas más comunes, se encuentran Facebook, Twitter, YouTube, Flickr e Instagram (Barría et al. 2016a). Sobre Twitter, existe una serie de estudios que se enfocan en analizar el contenido político en la red e, incluso, estudios que buscan realizar predicciones electorales con base en la actividad de los usuarios (e.g. Congosto y Aragón 2012; González-Bustamante 2015b; Grant et al. 2010; Himelboim et al. 2013; Jackson 2013; Small 2011; Straus et al. 2013; Tumasjan et al. 2010).

El uso de redes sociales en campañas virales y en procesos de branding no necesariamente implica un acercamiento entre el candidato y el elector. González-Bustamante y Henríquez (2013) indican que los encargados de una campaña digital pueden optar por convertir las nuevas tecno- 
logías y las redes sociales en una herramienta de marketing, generando una participación política digital efímera y ficticia. En este contexto, el spin doctoring ${ }^{4}$ de la política tradicional puede ser actualizado gracias a las nuevas tecnologías, dando lugar a herramientas más invasivas y perversas que involucran solo la identificación de mensajes y símbolos digitales, situación que puede darse, especialmente, en plataformas donde la extensión de los mensajes es limitada como Twitter. Esto no es descabellado, ya que los procesos de branding facilitan la encapsulación de información, afectando las decisiones a través de una asociación de una marca con determinados atributos, generando apego emocional, lealtad e impulsando un consumo/identificación sostenido en el tiempo (Griff Round y Roper 2012).

Más allá de las implicancias detrás del uso de redes sociales en el marco de las campañas electorales, este fenómeno constituye una realidad palpable y creciente, la que desconoce barreras geográficas y tipos de elección ${ }^{5}$. El auge del uso de redes sociales y de todo el aparataje comunicacional ligado a las campañas digitales se vincula al éxito de Barack Obama en las elecciones presidenciales de Estados Unidos. Obama reclutó para su campaña a un grupo de jóvenes que habían participado en exitosas compañías estadounidenses ligadas a la industria tecnológica, pero lo más relevante es que los ubicó a la par con las estructuras de la campaña tradicional (GonzálezBustamante y Henríquez 2013). Podemos señalar con propiedad que Obama llevó adelante una verdadera campaña digital y no solo "digitalizó” su campaña presencial'.

\section{LA EXPANSIÓN DE LA ESFERA DIGITAL EN CHILE Y EL USO DE REDES SOCIALES}

El porcentaje de personas que utilizan Internet y las suscripciones de banda ancha por número de habitantes en Chile son de los más altos de América Latina, junto con Argentina y Uruguay. Lo mismo sucede con el acceso a la telefonía móvil, tanto así que existen más suscripciones que

\footnotetext{
${ }^{4} \mathrm{El}$ spin o spinning es un concepto anglosajón vinculado a la necesidad de los gobiernos de dar a conocer decisiones de forma favorable, generando credibilidad. En este contexto, los spin doctors son los expertos que utilizan dicha técnica, aunque el término en algunas oportunidades puede ser usado de forma peyorativa para referirse a los asesores en relaciones públicas especializados en “curvar la realidad” (Serpa 2015; Tironi y Cavallo 2007).

${ }^{5}$ Esto está condicionado por variables sociodemográficas, tal como sugiere la literatura relacionada con el uso de tecnologías y sobre participación política. Por otra parte, también depende de la visibilidad de la campaña electoral, tal como hemos revisado.

${ }^{6}$ De forma similar, posteriormente, Barack Obama impulsó el gobierno abierto como concepto y práctica política con el memorándum sobre el tema que dictó en 2009 (Barría et al. 2016b).
} 
habitantes (Barría et al. 2016a; González-Bustamante 2015a). La esfera digital en Chile se ha expandido y esto ha impactado en la forma en que los chilenos se informan, pues durante la última media década, Internet ha ganado terreno como un canal habitual para consumir información, a pesar de no haber desplazado a los medios más tradicionales como la televisión y la radio (Arriagada et al. 2010; González-Bustamante 2014a; González-Bustamante y Soto 2016). A esto se agrega que, desde temprano, los usuarios de Internet han visto en ella una posibilidad de estar informados y en contacto con el sistema político. A modo de ejemplo, desde 2003, el Senado chileno opera una aplicación (Senador Virtual) que da la opción a los ciudadanos de opinar sobre proyectos de ley bajo discusión (Araya y Barría 2009). Estas condiciones han favorecido, también, un aumento sostenido en el uso de redes sociales. Hoy, plataformas como Twitter son bastante utilizadas por las autoridades, lo que ha contribuido a que exista un debate más directo entre representantes y representados en Chile (Fábrega y Paredes 2013; González-Bustamante 2015b).

En lo que respecta al uso electoral de redes sociales, se puede advertir que la campaña digital de Obama tuvo una repercusión casi inmediata en Chile. Durante la campaña presidencial de 20092010, los principales candidatos se preocuparon de desarrollar una campaña digital. El comando más exitoso fue el de Sebastián Piñera, quien precisamente fue electo Presidente, realizando un gran despliegue en cuanto a las diversas plataformas usadas, logrando un excelente posicionamiento (González-Bustamante y Henríquez 2013). Lo mismo se repitió en la campaña presidencial de 2013. En las primarias de junio de 2013, previas a la elección de fin de ese año, se advierte que la red se dinamiza con un gran incremento de actividad frente a la elección. Además, las cuentas de los distintos candidatos ganan una gran cantidad de seguidores y suelen verificar una intensa actividad en Internet, tanto así que los mensajes de los candidatos fueron propagados más de 20 mil veces en las dos semanas previas a la primaria y sus cuentan ganaron en promedio cerca de 90 mil nuevos seguidores (González-Bustamante 2014b). Lo mismo sucede cuando Michelle Bachelet asume como candidata presidencial para un segundo mandato. Se advierte que en Twitter, la actividad se intensifica y la conversación entre usuarios se polariza y se vuelve agresiva (González-Bustamante 2015b). Un elemento interesante de la evidencia empírica sobre el arribo de Bachelet a la campaña 
presidencial chilena de 2013, es que la actividad en la red se dinamiza y, en general, tiende a ser contraria a la candidata, lo cual resulta extraño ya que ella estaba bastante bien posicionada en las encuestas de opinión y, posteriormente, ganó las primarias y las elecciones presidenciales con un amplio margen de votación. Lo anterior sugiere, tal como indica González-Bustamante (2015b), que la actividad en Twitter no resulta ser un buen indicador de opinión pública.

El uso de redes sociales en campañas electorales se ha incrementado exponencialmente, sin embargo, no es el único uso para estas plataformas. Existen casos recientes donde estas han sido ocupadas como herramientas para la acción colectiva (Barría et al. 2016a). Por ejemplo, algunas organizaciones no gubernamentales han sido exitosas en utilizarlas para diseminar sus posturas, incorporar adherentes y, gracias a esto, posicionarse como actores relevantes en discusiones de política pública (Araya y Barría 2012). De igual forma, existe un activismo político eminentemente digital; ejemplos de esto son anticampañas digitales contra determinados proyectos de ley y campañas a favor de realizar cambios constitucionales. En este contexto, encontramos la anticampaña contra la fallida Ley Hinzpeter, proyecto que buscaba endurecer penas para actividades de protesta. También la campaña Marca tu Voto AC, enfocada en promover una Asamblea Constituyente en Chile. Destacan otras campañas para desincentivar o promover el voto en las elecciones generales, tales como Yo no Presto el Voto, impulsada por la Asamblea Coordinadora de Estudiantes Secundarios (ACES) o Haz tu Voto Volar, que buscaba la aprobación del voto de chilenos en el extranjero7 ${ }^{7}$

Por otra parte, una segunda forma de utilizar las redes sociales más allá del plano electoral tiene relación con la disminución de brechas en la mediación entre gobernantes y gobernados (Barría et al. 2016a). Al revisar las conversaciones políticas en Twitter, por ejemplo, se ve un incremento exponencial desde 2009 en adelante. En este contexto, estas plataformas digitales no solo se dinamizan ante la eventualidad de una elección como bien hemos revisado, sino que, además, se dinamizan ante hitos políticos relevantes. Un ejemplo de esto es el incremento de

${ }^{7}$ Para profundizar en estos ejemplos véase Millaleo y Cárcamo (2014), González-Bustamante (2014a) y Barría et al. (2016a). También existen otros casos relacionados con la forma en que las nuevas tecnologías permiten a los ciudadanos organizarse con el fin de incidir en los procesos de formulación de políticas públicas. En este sentido, el caso de Educación 2020, movimiento enfocado en temas educacionales, es un buen ejemplo. Para más detalles véase Araya y Barría (2012). 
los flujos comunicacionales durante la primera cuenta pública del segundo mandato de Michelle Bachelet en mayo de 2014 que observan Barría et al. (2016a): en una sola semana se emitieron 176.414 mensajes, los cuales fueron propagados 4.511 .995 veces por 52.217 usuarios. Además, el día de la cuenta pública, el 21 de mayo, fueron emitidos 30.033 mensajes, los cuales fueron propagados 573.611 veces (Figura 1).

Estas cifras dan cuenta de un gran incremento en el uso de redes sociales, ya que en 2009, alrededor de tres mil usuarios comentaban un debate televisado (González-Bustamante y Henríquez 2013), por lo cual, en cinco años, la participación en estas instancias digitales se ha incrementado en más de un $1.640 \%$, lo cual resulta asombroso ${ }^{8}$.

Ahora bien, como hemos revisado, la actividad en la red no necesariamente se condice con los patrones de opinión pública de la ciudadanía, situación que tiene relación con la "representatividad" de lo que sucede en la esfera digital. Un claro ejemplo de esto es que, durante la cuenta pública de 2014, un 74,4 \% de los mensajes se emitieron desde la capital y, además, se concentraron en las comunas de mayor nivel socioeconómico de la ciudad (Figura 2). Este margen de actividad se mantuvo durante 2015, muestra de esto es que, al realizar una medición el 21 de mayo de 2014 a las 11:30 horas (hacia el final del discurso), se verifican 22.347 menciones sobre la cuenta pública. A la misma hora, el año siguiente, la actividad en la red supera las 30 mil menciones, es decir, se registra un incremento de un $34 \%$. En definitiva, pareciera que el escepticismo del ciberpesimismo asociado a la idea de que la esfera digital replica las desigualdades presenciales, siguiendo a Mossberger et al. (2008) y Nam (2012), se ve plasmado en esta situación.

Todo parece indicar que el uso de estas plataformas aún no alcanza un techo, ya que otros hitos políticos después de la cuenta pública de 2015 alcanzaron cifras superiores a las 50 mil menciones en un solo día. Estos hitos, que también dinamizaron la red, tienen relación con shocks sobre el sistema político. En Chile, los períodos de crisis y shocks, como las crisis económicas y los escándalos de corrupción, suelen tener efectos relativamente evidentes sobre el sistema político ${ }^{9}$.

${ }^{8}$ Este cálculo se realiza comparando la actividad de una semana de mayo de 2014 con la actividad de un debate televisado de 2009. El problema de esta comparación es que el debate se realiza en un solo día. Al ajustar la escala para que la comparación sea más pertinente, la cifra supera el $148 \%$.

${ }^{9}$ Un ejemplo de esto es cómo los shocks afectan la rotación en los gabinetes, así lo evalúan González-Bustamante 
En este contexto, los últimos dinamizan los flujos comunicacionales y las conversaciones políticas en Internet.

Desde fines de 2014 y durante 2015, Chile ha enfrentado significativos escándalos de corrupción vinculados a financiamiento ilegal de campañas políticas y serios conflictos de interés que han involucrado, entre otros, al hijo de la presidenta Bachelet. Los casos más connotados son CavalDávalos, Penta y Soquimich ${ }^{10}$. Entre diciembre de 2014 y marzo de 2015, la empresa Brandmetric realizó un seguimiento de las reacciones sobre estos casos y se registran dos hitos relevantes: el 12 de febrero de 2015, cuando la Superintendencia de Bancos e Instituciones Financieras entregó su balance sobre el caso Caval-Dávalos, con 95.163 menciones; y el 7 de marzo, cuando los Tribunales de Justicia decretaron prisión preventiva para los involucrados en el caso Penta, con más de 75 mil menciones ${ }^{11}$.

\section{CONCLUSIONES}

En este capítulo hemos realizado un breve recorrido teórico sobre diversos tópicos relacionados con el avance de las tecnologías de información y su influencia en fenómenos electorales y en la emisión de opiniones políticas. Además, hemos ofrecido datos y evidencia sobre la actividad en redes sociales en campañas electorales recientes y otros hitos políticos como cuentas públicas o shocks sobre el sistema político, particularmente escándalos de corrupción. Este recorrido teórico-descriptivo nos permite destacar que, si bien en Chile, durante los últimos años el uso de redes sociales tiende a vincularse a una dimensión político-electoral -la que suele estar relacionada con procesos de branding y encapsulación de mensajes-, estas plataformas también son frecuentemente utilizadas por los ciudadanos para realizar una "conversación política" sobre ciertas coyunturas, particularmente sobre actos republicanos como una cuenta pública y shocks como casos de corrupción.

y Olivares (2015; 2016a; 2016b).

${ }^{10} \mathrm{El}$ caso Caval-Dávalos se refiere a un posible tráfico de influencias que involucra a Sebastián Dávalos, hijo de la presidenta Michelle Bachelet. El caso Penta y su arista Soquimich se relacionan con situaciones de fraude al Fisco y financiamiento ilegal de campañas electorales.

${ }^{11}$ Otros hitos relevantes durante 2015 fueron el cambio de gabinete en mayo y el anuncio del proceso constituyente en octubre, donde ambos alcanzaron más de 20 mil menciones en un día. 
Lo anterior es consistente con las conclusiones de Barría et al. (2016a), que indican que las redes sociales surgen como espacios "libres", en los cuales se expresa una gran cantidad de opiniones. Si bien en este capítulo hemos ofrecido algunas luces sobre aquel fenómeno, nos enfocamos en un análisis de corte exploratorio y casi puramente estadístico-descriptivo, lo que impone el desafío de avanzar en estudios que vayan más allá del "análisis algorítmico", siguiendo las ideas de Couldry y Powell (2014) sobre big data al servicio de la gobernanza moderna. Asimismo, conviene centrarse en cuestiones más reflexivas, que permitan entender mejor e incluso canalizar esta participación atomizada que, de momento, parece ser de baja intensidad. Redes sociales como Twitter han creado una "plaza pública virtual" que provoca que las campañas no tengan únicamente un componente activo - lo que el candidato y su equipo quieren transmitir- sino también una dimensión pasiva, esto es, el flujo de información sobre un candidato generado por otros: sus atributos, historia de vida y propuestas. Ello implica un desafío para los profesionales que se dedican a llevar adelante campañas, pero también impone nuevos temas de estudio para la academia.

Por último, el desafío en una dimensión vinculada al gobierno electrónico se encuentra en cómo canalizar esas opiniones y contribución libre de baja intensidad hacia instancias de participación efectivas. De igual forma, otro elemento para tener en cuenta es cómo gestionar la colaboración de ciertos grupos que, en ocasiones, no buscan hacer escuchar su voz para influir en la forma en que ciertos programas operan, sino que actúan para bloquearlos o, incluso, eliminarlos.

\section{AGRADECIMIENTOS}

Agradecemos especialmente a Alejandro Olivares y Carla Cisternas por sus valiosos comentarios. Evidentemente los errores u omisiones son de nuestra exclusiva responsabilidad.

\section{Referencias}

Altman, D. y Luna, J. P. (2009). "E-government América Latina: de la evidencia macro-nacional a la evidencia micro-municipal en Chile." Democracia e Participação em Rede: Europa e América do Sul, G. Cardoso, B. Amadeo, P. Pereira, y R. Espanha, eds., Centro de Investigação e Estudos de Sociologia-Instituto Universitário de Lisboa, Lisboa. 
Araya, E. y Barría, D. (2009). "E-participación en el Senado chileno: ¿aplicaiones deliberativas?." Convergencia. Revista de Ciencias Sociales, (51), 239-268.

Araya, E. y Barría, D. (2012). "Internet, investigación e influencia. Las estrategias de Educación 2020.” Impacto 2.0. Nuevos mecanismos para vincular investigación académica y políticas públicas, B. Girard y E. Acosta, eds., Comunica, Montevideo.

Araya, E., Barría, D., y Campos, G. (2009). "Internet and Political Parties in Chile." Systems Thinking and E-Participation: ICT in the Governance of Society, J. R. Cordoba-Pachón y A. E. Ochoa-Arias, eds., Hershey, Nueva York.

Arriagada, A. y Navia, P. (2013). "Medios y audiencias, ciudadanos y democracia." Intermedios: medios de comunicación y democracia en Chile, A. Arriagada y P. Navia, eds., Ediciones UDP, Santiago.

Arriagada, A., Navia, P., y Schuster, M. (2010). “Consumo luego pienso, o pienso y luego consumo? Consumo de medios, predisposición política, percepción económica y aprobación presidencial." Revista de Ciencia Política, 30(3), 669-695.

Barría, D., González-Bustamante, B., y Araya, E. (2016a). "Democracia electrónica y participación digital. Avances y desafíos.” Tecnologías de información y comunicación en la administración pública. Conceptos, enfoques, aplicaciones y resultados, J. R. Gil-García, J. I. Criado, y J. C. Telléz, eds., INFOTEC, Ciudad de México.

Barría, D., González-Bustamante, B., y Cisternas, C. (2016b). “Gobierno abierto en América Latina y España. Análisis de la producción en español sobre el tema." Ponencia presentada en el XXI Congreso Internacional del CLAD sobre la Reforma del Estado y la Administración Pública, Santiago.

Bruns, A. y Burgess, J. (2012). "Researching New Discussion on Twitter. New Methodologies." Journalism Studies, 13(5-6), 801-814.

Cammaerts, B. (2012). "Protest Logics and the Mediation Opportunity Structure." European Journal of Communication, 27(2), 117-134.

Castells, M. (2012). Networks of Outrage and Hope. Social Movements in the Internet Age. Polity 
Press, Cambridge.

Congosto, M. L. y Aragón, P. (2012). “Twitter, del sondeo a la sonda. Nuevos canales de opinión. Nuevos métodos de análisis.” Más Poder Local, (12), 50-56.

Couldry, N. y Powell, A. (2014). "Big Data From the Bottom Up.” Big Data \& Society, 1(2), 1-5.

Del Valle, N. (2016). "Pluralismo informativo de los medios digitales escritos en Chile. Apuntes de investigación.” Serie Política, Gestión y Políticas Públicas, (3), 1-29.

Earl, J. y Kimport, K. (2011). Digitally Enabled Social Change. Activism in the Internet Age. MIT Press, Massachusetts.

Fábrega, J. y Paredes, P. (2013). "La política chilena en 140 caracteres.” Intermedios: medios de comunicación y democracia en Chile, A. Arriagada y P. Navia, eds., Ediciones UDP, Santiago.

González-Bustamante, B. (2014a). “Activismo digital, redes sociales e intermediación.” Mediaciones del sistema político frente al activismo digital, S. Millaleo y P. Cárcamo, eds., FDD, Santiago.

González-Bustamante, B. (2014b). "Nuevos medios y política digital. El caso de las primarias presidenciales chilenas de 2013." Nuevos medios y comunicación política digital, G. Sibaja, ed., FESJT, San José.

González-Bustamante, B. (2015a). "Consumo de medios y formas de participación política en Argentina, Chile y Uruguay." Ponencia presentada en el XII Congreso Argentino de Ciencia Política, Mendoza.

González-Bustamante, B. (2015b). "Evaluando Twitter como indicador de opinión pública. Una mirada al arribo de Bachelet a la presidencial chilena 2013.” Revista SAAP, 9(1), 119-141.

González-Bustamante, B. y Henríquez, G. (2013). “Chile: la campaña digital 2009-2010.” Comunicación Política \& Campañas Electorales en América Latina, I. Crespo y J. del Rey, eds., Biblos, Buenos Aires.

González-Bustamante, B. y Olivares, A. (2015). "Rotación de subsecretarios en Chile. Una exploración de la segunda línea gubernamental (1990-2014).” Revista de Gestión Pública, IV(2), $151-190$. 
González-Bustamante, B. y Olivares, A. (2016a). “A rotatividade de subsecretários dos ministérios no Chile (1990-2014)." Newsletter, Observatório de elites políticas e sociais do Brasil, nusp/ufpr, 3(5), 1-19.

González-Bustamante, B. y Olivares, A. (2016b). "Cambios de gabinete y supervivencia de los ministros en Chile durante los gobiernos de la Concertación (1990-2010)." Colombia Internacional, (87), 81-108.

González-Bustamante, B. y Sazo, D. (2015a). “Branding político.” Diccionario Enciclopédico de Comunicación Política, I. Crespo, O. D’Adamo, V. García, y A. Mora, eds., CEPC, Madrid.

González-Bustamante, B. y Sazo, D. (2015b). “Campaña viral.” Diccionario Enciclopédico de Comunicación Política, I. Crespo, O. D’Adamo, V. García, y A. Mora, eds., CEPC, Madrid.

González-Bustamante, B. y Soto, D. (2016). "Pluralismo en los medios digitales escritos en Chile. Una exploración de casos clave.” Serie Política, Gestión y Políticas Públicas, (2), 1-16.

Grant, W. J., Moon, B., y Grant, J. B. (2010). “Digital Dialogue? Australian Politicians' use of the Social Network Tool Twitter.” Australian Journal of Political Science, 45(4), 579-604.

Griff Round, D. J. y Roper, S. (2012). "Exploring Consumer Brand Name Equity: Gaining Insight Through the Investigation of Response to Name Change." European Journal of Marketing, 46(7-8), 938-951.

Hermida, A., Fletcher, F., Korell, D., y Logan, D. (2012). "Share, Like, Recommend. Decoding the Social Media News Consumers.” Journalism Studies, 13(5-6), 815-824.

Himelboim, I., McCreery, S., y Smith, M. (2013). "Birds of a Feather Tweet Together: Integrating Network and Content Analyses to Examine Cross-Ideology Exposure on Twitter." Journal of Computer-Mediated Communication, 18(2), 40-60.

Jackson, S. M. (2013). “Organization as an Impediment to Effective Campaigning. The Australian Greens, Electronic Campaigning and the 2010 Federal Election.” Information, Communication \& Society, 16(1), 82-104.

Johnson-Cartee, K. S. y Copeland, G. A. (1991). Negative Political Advertising: Coming of Age. Routledge, Nueva York. 
Kaplan, A. M. y Haenlein, M. (2011). “Two Hearts in Three-Quarter time: How to Waltz the Social Media/Viral Marketing Dance.” Business Horizons, 54(3), 253-263.

Linders, D. (2012). "From E-Government to We-Government: Defining a Typology for Citizen Coproduction in the Age of Social Media." Government Information Quarterly, 29(4), 446-454.

Marsh, D. y Fawcett, P. (2011). "Branding, Politics and Democracy.” Policy Studies, 32(5), 515-530.

Millaleo, S. y Cárcamo, P. (2014). Mediaciones del sistema político frente al activismo digital. FDD, Santiago.

Millaleo, S. y Velasco, P. (2013). Activismo digital en Chile. Repertorios de contención e iniciativas ciudadanas. FDD, Santiago.

Mossberger, K., Tolbert, C. J., y McNeal, R. S. (2008). Digital Citizenship: The Internet, Society, and Participation. MIT Press, Massachusetts.

Nam, T. (2012). "Dual Effects of the Internet on Political Activism: Reinforcing and Mobilizing." Government Information Quarterly, 29(1), S90-S97.

Nie, N. H. (2001). "Sociability, Interpersonal Relations, and the Internet. Reconciling Conflicting Findings." American Behavioral Scientist, 45(3), 420-435.

Rheingold, H. (2000). Tools for Thought: The History and Future of Mindexpanding Technology. MIT Press, Massachusetts.

Rojas-Martín, F. y Criado, J. I. (2015). “Avanzando en la medición de las redes sociales digitales. Una propuesta para su análisis desde una perspectiva institucionalista." Revista de Gestión Pública, IV(1), 43-64.

Sagredo, R. (2001). Vapor al norte, tren al sur. El viaje presidencial como práctica política en Chile. Siglo XIX. Centro de Investigaciones Diego Barros Arana, Santiago.

Sandoval-Almazán, R. y Gil-García, J. R. (2012a). “Are Government Internet Portals Evolving Towards more Interaction, Participation, and Collaboration? Revisiting the Rhetoric of EGovernment among Municipalities.” Government Information Quarterly, 29(1), S72-S81.

Sandoval-Almazán, R. y Gil-García, J. R. (2012b). “Gestión de la tecnología. Una exploración del uso de las redes sociales en los gobiernos estatales de México.” Revista de Gestión Pública, I(2), 
273-309.

Serpa, M. (2015). “Spin Doctor.” Diccionario Enciclopédico de Comunicación Política, I. Crespo, O. D’Adamo, V. García, y A. Mora, eds., CEPC, Madrid.

Small, T. A. (2011). "What the Hashtag? A Content Analysis of Canadian Politics on Twitter." Information Communication \& Society, 14(6), 872-895.

Straus, J. R., Glassman, M. E., Shogan, C. J., y Navarro, S. (2013). “Communicating in 140 Characters or Less: Congressional Adoption of Twitter in the 111th Congress." PS: Political Science \& Politics, 46(1), 60-66.

Strömbäck, J. (2008). "Four Phases of Mediatization: An Analysis of the Mediatization of Politics." The International Journal of Press/Politics, 13(3), 228-246.

Tironi, E. y Cavallo, A. (2007). Comunicación estratégica. Vivir en un mundo de señales. Aguilar Chilena Ediciones, Santiago.

Tumasjan, A., Sprenger, T. O., Sandner, P. G., y Welpe, I. M. (2010). "Predicting Elections with Twitter: What 140 Characters Reveal about Political Sentiment." Ponencia presentada en la Fourth International AAAI Conference on Weblogs and Social Media, Washington D.C. 


\section{Índice de figuras}

1. Mensajes en la red durante la primera cuenta pública del segundo gobierno de Michelle Bachelet (19 al 26 de mayo de 2014). Fuente: Elaboración propia con datos extraídos de la Application Programming Interface (API) de Twitter. . . . . . 19

2. Ubicación de emisores concentrados en Santiago de Chile $(n=22.347)$. Nota: Se indican solo las menciones localizadas en Santiago de Chile. Este seguimiento se realizó con base en las aproximaciones metodológicas de Bruns y Burgess (2012) para una extracción de una gran cantidad de datos con la API de Twitter. La mayoría de los trabajos suelen extraer datos de esta forma (e.g. Congosto y Aragón 2012; Barría et al. 2016a; González-Bustamante 2014b; 2015b). Fuente: Elaboración propia con datos extraídos de la API de Twitter. . . . . . . . . . . . . . . . 20 


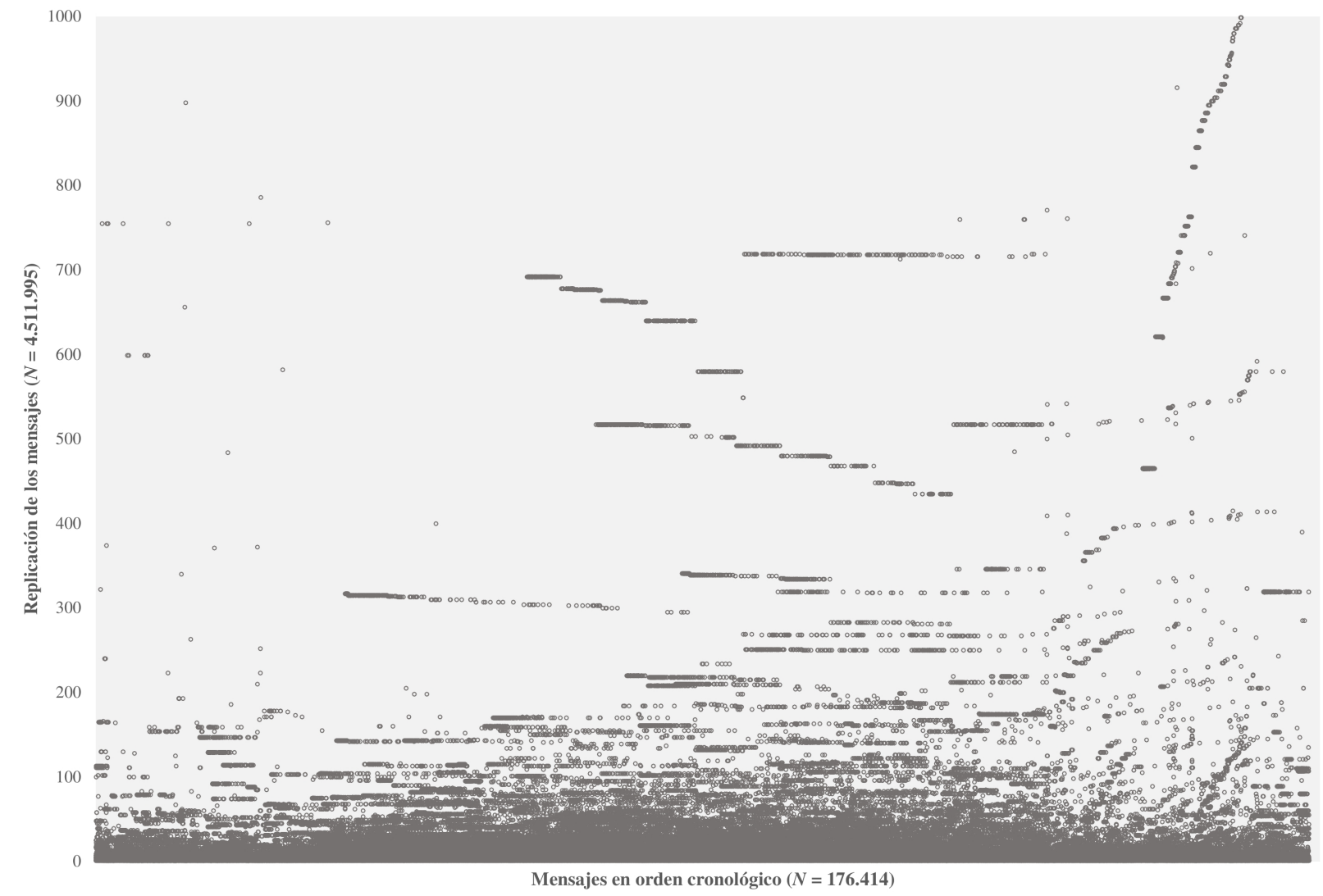

Figura 1. Mensajes en la red durante la primera cuenta pública del segundo gobierno de Michelle Bachelet (19 al 26 de mayo de 2014). Fuente: Elaboración propia con datos extraídos de la Application Programming Interface (API) de Twitter. 


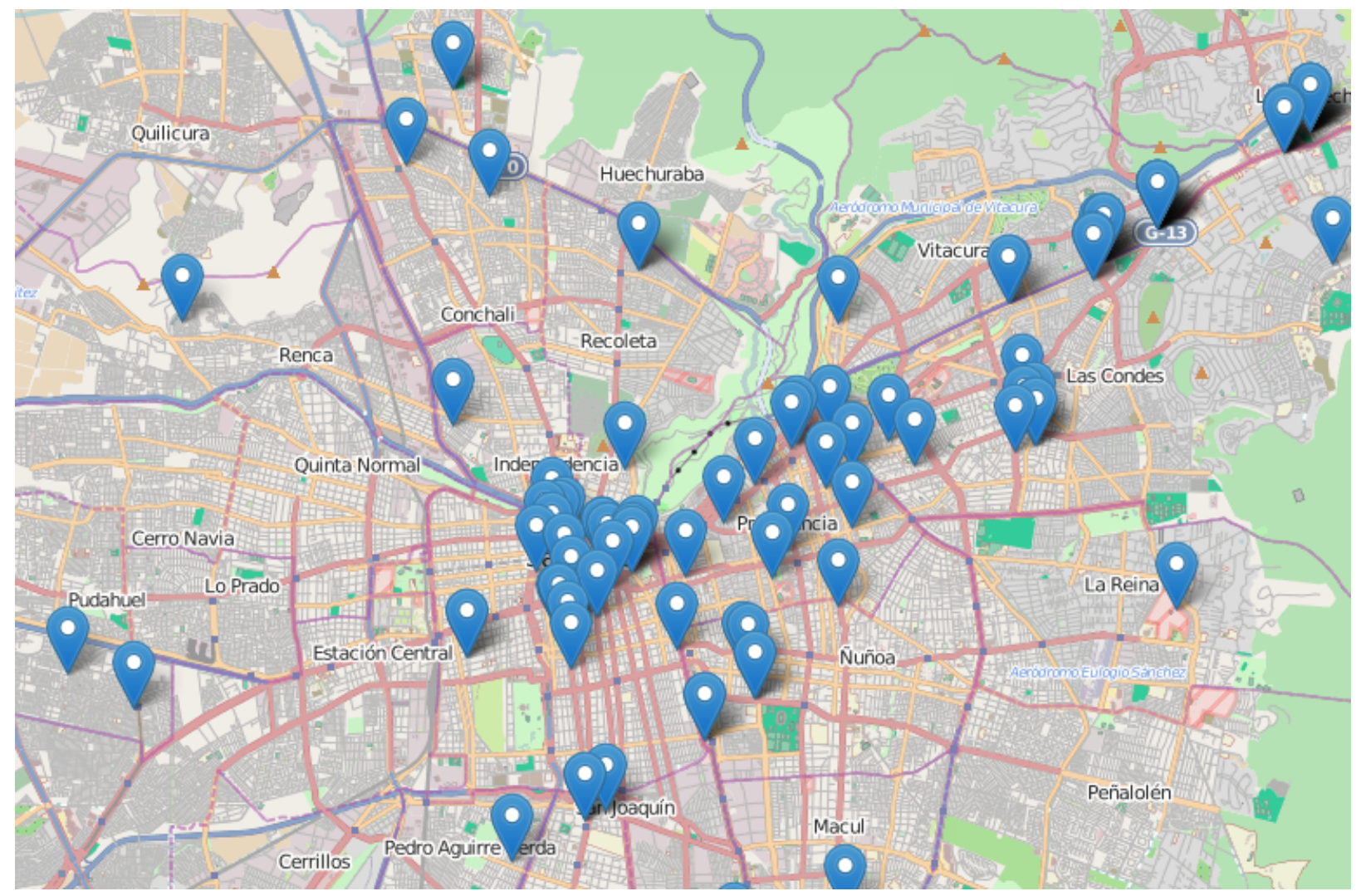

Figura 2. Ubicación de emisores concentrados en Santiago de Chile $(n=22.347)$. Nota: Se indican solo las menciones localizadas en Santiago de Chile. Este seguimiento se realizó con base en las aproximaciones metodológicas de Bruns y Burgess (2012) para una extracción de una gran cantidad de datos con la API de Twitter. La mayoría de los trabajos suelen extraer datos de esta forma (e.g. Congosto y Aragón 2012; Barría et al. 2016a; González-Bustamante 2014b; 2015b). Fuente: Elaboración propia con datos extraídos de la API de Twitter. 